\title{
Norois
}

Environnement, aménagement, société

$249 \mid 2018$

Patrimoine, vignoble, continuité écologique, transition énergétique, anthropologie des catastrophes

\section{Villes et campagnes en relations. Regards croisés Nords-Suds}

Isabelle Duvernoy

\section{CpenEdition}

Journals

Édition électronique

URL : https://journals.openedition.org/norois/7234

DOI : $10.4000 /$ norois.7234

ISBN : 978-2-7535-7773-2

ISSN : $1760-8546$

Éditeur

Presses universitaires de Rennes

Édition imprimée

Date de publication : 31 décembre 2018

Pagination : 89-90

ISBN : 978-2-7535-7771-8

ISSN : 0029-182X

Référence électronique

Isabelle Duvernoy, "Villes et campagnes en relations. Regards croisés Nords-Suds », Norois [En ligne], 249 | 2018, mis en ligne le 31 décembre 2018, consulté le 08 janvier 2022. URL : http:// journals.openedition.org/norois/7234; DOI : https://doi.org/10.4000/norois.7234 


Presses
Universitaires
de Rennes

\section{COMPTE RENDU BIBLIOGRAPHIQUE}

\section{Martine Berger et Jean-Louis ChalÉARD (dir.), 2017. Villes et campagnes en relations. Regards croisés Nords-Suds, Paris, Karthala, 299 p.}

Ce livre regroupe 15 communications portant sur des études de cas dans cinq continents, présentées au colloque du même titre organisé par le Labex DynamiTe en 2015, entourées par quatre grandes synthèses. Trois textes introduisent le livre, le premier (Berger et al.) pose la question des convergences entre Nords et Suds, les deux suivants construisent une vision historique de l'étude et de la compréhension des relations villes-campagnes par la géographie en France (M. Berger), et dans les pays des Suds (Chaléard). La conclusion (Magrin et Poulot) reprendra ces différents éléments en proposant et discutant quatre questionnements pour les études futures : « la pertinence des catégories », " les échelles et les acteurs » « la question agricole » et son renouvellement, «l'apport des regards croisés », (p. 278).

Mais ces questionnements trouvent des illustrations pertinentes dans les communications. Il en va ainsi des catégories, qu'elles soient de ville, de campagne ou d'agriculture urbaine, dont les auteurs questionnent l'universalité, et dont ils soulignent les effets performatifs (Pestaña et Pantz, Beuf). Par rapport à la question incisive posée dans la conclusion, «Les chercheurs sont-ils là pour contester les catégories ou pour les consommer? » (ibid., p. 288), ces travaux montrent qu'une troisième posture est fructueuse : comprendre comment ces catégories sont appropriées, voire imposées, contestées ou négociées localement (Mumenthaler et Salomon Cavin; Barthe et al.).

SOS SIADIRICION DE

Martine Berger et Jean-Louis Chaléard

\section{Villes et campagnes en relations}

Regards croisés Nords-Suds

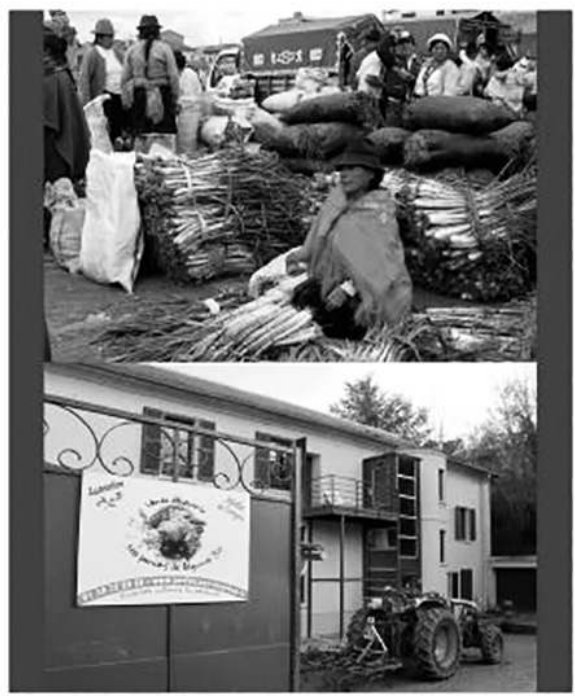

KARTHALA 
S'agissant du couple ville-campagne, la question de leurs interactions ne peut s'affranchir de celle des échelles d'observation, mais également des échelles de références des constructions territoriales, que celles-ci adoptent de nouvelles mailles pour penser la ville ou le périurbain (Bonnin-Oliveira), ou qu'elles se positionnent simultanément à plusieurs échelles (Berroir et al.), par exemple quand il s'agit de concilier une reconnaissance comme ville globale et l'interpénétration de la ville et de la campagne (Landy). Cette pluralité des échelles, et leur jeu réciproque, se lit également dans la description fine de pratiques habitantes (Robert-Bœuf; Tommasi) et des formes de mobilités (Ndao et Lombard; Pestaña et Pantz; Berger et al.) qui s'affranchissent des modèles uniques.

Dans cet ouvrage, la question agricole est saisie par celle de l'urbanisation. La variété des travaux présentés permet de saisir les nouvelles attentes portant sur l'agriculture pour la fabrique et la qualification de la ville mais également les fonctions que la ville peut jouer pour l'espace rural (Dia-Ndiaye et Ninot), y compris son approvisionnement alimentaire (Ndao et Lombard). Ils permettent d'illustrer de nouvelles réciprocités entre l'agriculture et les classes moyennes en périphérie de ville, montrant parfois une convergence des transformations entre les Nords et les Suds : agriculture de loisir, mise en tourisme, urbanisation de la nature (Leloup; Rousseau et al.). Ces chapitres permettent d'être attentifs à deux questions en miroir : Comment étendre ces relations aux autres habitants des villes (Girard)? Ces transformations agricoles sont-elles de simples « compensations » par rapport aux enjeux qui portent sur l'activité agricole dans un contexte d'urbanisation (Mumenthaler et Salomon Cavin)?

L'idée de croiser les regards portant sur des territoires des Suds et des Nords donne à voir les différences d'enjeux à côté de la pertinence des mêmes questionnements (sur l'urbanisation et ses formes, sur les transformations agricoles en proximité de ville etc.). À la lecture de l'ouvrage, apparaît peut-être une différence de lecture, la question des conflits sociaux et des inégalités sociales paraît plus prégnante dans les travaux portant sur les Suds que sur les Nords. Comme le rappelle la conclusion à propos de l'agriculture urbaine, les enjeux et les inégalités ne sont pas de même ampleur (Magrin et Poulot). Néanmoins, au-delà des modèles de ville, de relations villes-campagnes, les questions " pour qui sont-ils pensés? ", " quels effets de sélection (sur les habitants, les agriculteurs)? " pourraient bien garder leur pertinence dans les Nords. Par ailleurs, cet ouvrage et sa conclusion incitent à un autre croisement ou hybridation des regards; en offrant une compilation des conceptualisations et des travaux de la géographie de langue française sur les relations villes-campagnes dans le monde, elles invitent à un dialogue avec des géographes travaillant dans d'autres langues et y construisant, peutêtre, d'autres conceptualisations de la ville, de la campagne et de leurs liens (Magrin et Poulot).

La diversité des études de cas, la pertinence de leurs questionnements, la richesse et la profondeur historique apportée par les quatre synthèses proposées rendent la lecture de ce livre nécessaire à qui s'intéresse aux relations villes-campagnes, à leur diversité, et à l'histoire des idées qui a accompagné leurs transformations tant dans les Nords que dans les Suds.
Isabelle DuvernoY INRA, umr 1248 Agir 